\title{
PARAMETRIC LIBRARY FOR RIBBED VAULTS INDEXING
}

\author{
M. Capone ${ }^{1}$, E. Lanzara ${ }^{1}$ \\ ${ }^{1}$ UNINA, University of Naples Federico II, 80134 Naples, Italy - (mara.capone, emanuela.lanzara)@unina.it
}

KEY WORDS: ribbed vaults, procedural modelling, HBIM, shape grammar, semantic, parametric objects library.

\begin{abstract}
:
This paper presents a part from one broader research project on ribbed vaults. The main goal is to generate a parametric objects library for ribbed vaults, suitable both for HBIM system, for structural analysis or for Cultural Heritage dissemination. Starting from Treatises study we have analyzed different classification system and different terminology used for ribbed vaults components in different languages, especially in English, French, Spanish and Italian, our aim is to improve a multilingual vocabularies. In our research we have defined an experimental workflow to generate a set of ribbed vaults library based on the geometric rules from treatises and a controlled vocabulary, the comparison of these 3D models with point clouds allows us to identify the rule used or to define a new rule and, therefore, to build complex parametric models based on reality-based surveys. We are improving our parametric model using different geometric rules from Spanish, French and English manuals. We can generate the realty based model using the same parametric model, in this case the input data is the ribs geometry extracted from the point cloud. We use a generative tool to analyze the curves from point cloud and to draw the borders. We are going to test our tool on some case studies for historical architectural elements indexing, for geometries reconstruction in HBIM environment and for point cloud segmentation in DL process.
\end{abstract}

\section{INTRODUCTION}

Parametric objects library of historical architectural elements is a very important step in more than one process, starting from segmentation of 3D Point Clouds with Deep Learning (DL) techniques to 3D modeling from Point Cloud. The main goal is to generate a 3D model, a digital twin, suitable both for HBIM system, for structural analysis or for Cultural Heritage dissemination. This 3D model is an "ideal model", with an appropriate level of detail, generated using procedural modeling techniques. We have to decompose historical building into architectural elements that can be clearly identified. We can do that using historical sources, architecture Manuals and scientific works. We can separate architectural elements, like domes, vaults, windows, etc. and classify them using specific criteria. Each element is composed of different components that we have to define and we can use for a semantic classification. One of the main question to deal with is the right term to refer to a given concept (architectonic elements and components) to correct indexing. In our research we have compared synonyms used for the same element or component from different sources (Manuals and scientific works) with Getty Vocabularies, in particular with the Art \& Architecture Thesaurus (AAT), that contains terms, synonyms, definitions, and relationships for objects, styles, materials, related to art, architecture, and other material culture. In this paper we present a part from one broader research project on ribbed vaults. Starting from Treatises study we have analyzed different classification system and different terminology used for ribbed vaults components in different languages, especially in English, French, Spanish and Italian (Figure 1). Improving a multilingual vocabularies is one of the our aim. The semantic classification of architectural elements, before the modelling phase, is one of the main step in order to avoid creating objects meaningless from an architectural point of view. The search for "generating geometries", sometimes hidden by decorative elements, is crucial to be able to see beyond the visible.

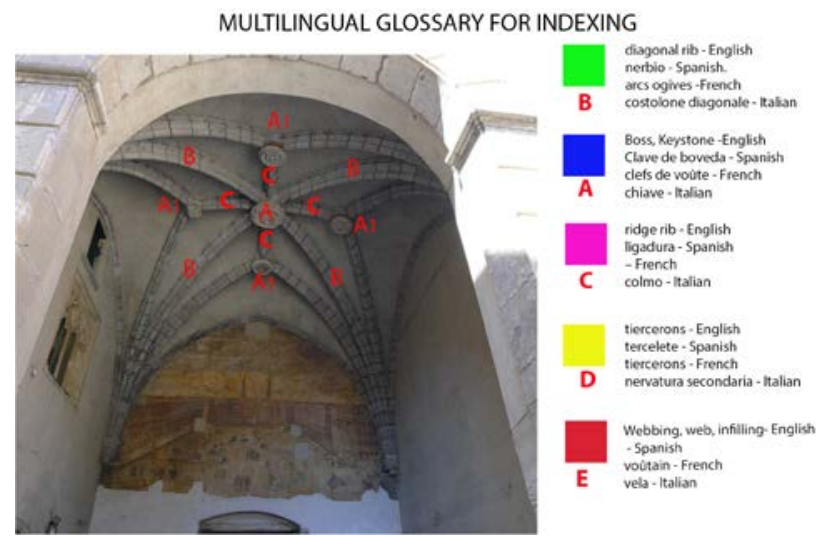

Figure 1. Terminology used for ribbed vaults components in different languages to improve a multilingual glossary.

Geometrical knowledge could be the start point for big data interpretation, in the process that from the point cloud allows us to define a synthetic geometric model. In our research we have defined an experimental workflow with the aim of generating a set of ribbed vaults library based on the geometric rules from treatises and a controlled vocabulary. The comparison of these 3D models with point clouds allows us to identify the rule used or to define a new rule and, therefore, to build complex parametric models based on reality-based surveys.

Workflow:

1. Ribbed vaults classification and elements definition for Semantic Segmentation: terminology from Treatises analysis (concepts definition) and Getty Vocabularies (Italian terminology for ribbed vault to improve multilingual Getty Vocabularies); 
2. Geometric rules definition for ribbed vaults design;

3. Algorithm for ribbed vaults generation based on different geometric rules (ideal model definition);

4. Algorithm for set points extraction from point cloud and geometry definition of extrusion lines;

5. Algorithm for ribbed vaults generation based on geometric primitives from point cloud (realty based models);

6. Tests for point cloud segmentation and 3D reconstruction.

\section{RIBBED VAULTS CLASSIFICATION}

\subsection{Ribbed vaults classification and elements definition for Semantic Segmentation}

Ribbed vaults classification, based on historical asset families, is the process starting point. The main difference between Roman Concrete vaults and gothic vaults are ribs. "Rib vault or ribbed vault is Gothic system of vaulting in which independent ribs are first constructed and then thin web of the vault proper is built in the panels or compartments they define, the conformation of each such web being determined by the contour of the ribs that bound it" (Fitchen, 1961). Starting from glossary by John Fitchen that is not a general dictionary of architectural terms but an explanatory and interpretative vocabulary designed to clarify the technical words used, we have done a classification based on this definition and on the geometry of the ribs. We have grouped ribbed vaults and, for each group, we have defined the components that can be modified from the standard definition. In this article we present in particular a study on Sexpartite, Quadripartite and Star Vaults.
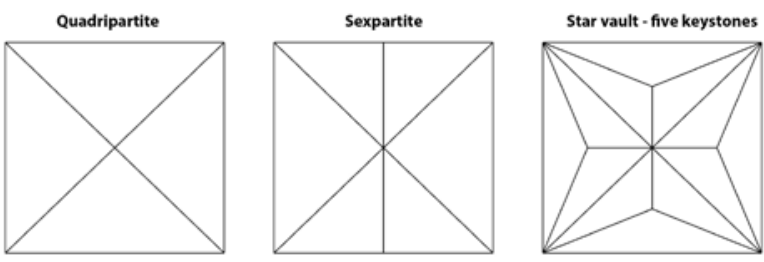

Figure 2. Ribbed Vaults classification

The first ribbed vaults classification is based on the evolution of this kind of vault starting from the simplest Quadripartite rib vault to Star vault (Figure 2). We can define:

a Quadripartite rib vault, a rib vault which is divided into four sections by two diagonal ribs; a Sexpartite rib vault, a rib vault which is divided into six sections by two diagonal ribs and one transverse arch and a Star vault or Stellar vault, a rib vault which is divided into more than six sections by ribs that divide angles at the vertex of the plan into more than two parts.

We can group these vaults in relation to the number of divisions of the plan angle (Cavallari, 1958) and in relation to the crown line that can be slightly curved, inclined or horizontal.

First we have defined all the terms and synonyms, the scientific and common terms for the same concept, for each element in different languages (diagonal rib, liernes, nervio, costolone....) then we have defined the geometry of each element (pointed arch, round arch....) and we have identified the parameters that can change to generate the different configurations (ribs shape, ridge shape...).

From comparison between sources (Glossary of Medieval Art and Architecture, John Fitchen glossary, Getty Vocabularies, Viollet-le-Duc Dictionaire, Cavallari Murat...) we have defined the main terms used for vaults for gothic vault construction and we have grouped the elements that compose a ribbed vault into main elements and components, that are the parts which the elements are composed by.

The main elements are: ribs, diagonal ribs, perimetral arches, transverse arches, tiercerons, ridge ribs and webs (Figure 3).

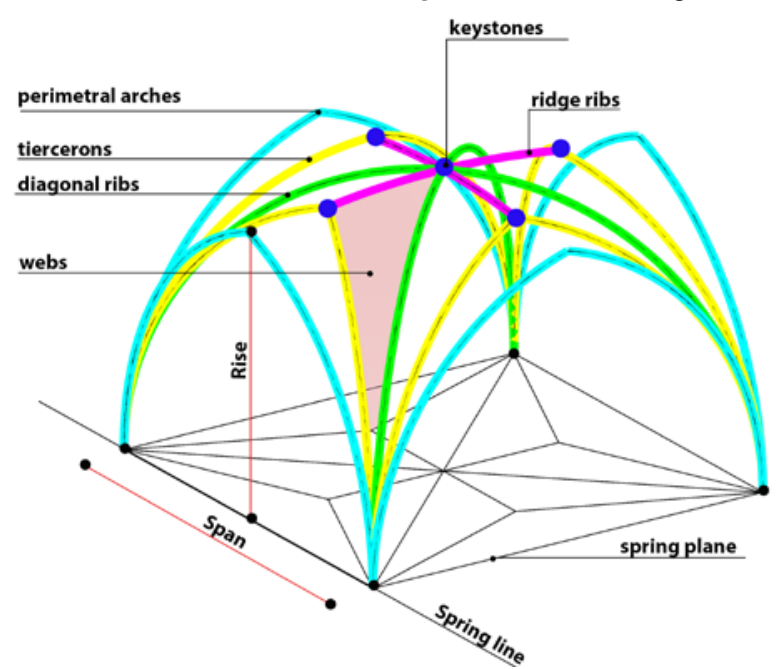

Figure 3. Main terms and main elements for indexing

The main components are: voussoir, boss or keystone and tasde-charge (Figure 4).

\section{Main terms}

Spring line and spring plane (of an arch or a vault): the line or the ideal plans at which an arch or vault begins to curve.

Rise (of an arch): the vertical distance between the spring line of an arch and the keystone.

Span (of an arch): the horizontal distance between the two supporting members of an arch.

\section{Elements - concept definition}

Rib: one of the salient stone arches that visually divides a Gothic vault into compartments (Fitcher, 1961);

Diagonal ribs: the ribs which mark the diagonals arches in a rib vault.

Perimetral arches or wall arches: the arches that are on the side of the plan. They may be wall arches when the surface are closed by a wall.

Transverse arches: supporting arch which runs across the vault from side to side, dividing the bays. It usually projects down from the surface of the vault. They are usually between adjacent vaults.

Tierceron: a major rib in a complex rib vault. Tiercerons spring from the main springers.

Lierne: a minor rib in a complex rib vault. Liernes do not spring from the main springers.

Ridge rib: a rib which on the crown-line of the vault.

Web, infilling or webbing: the vault surface between the ribs of a rib vault. 


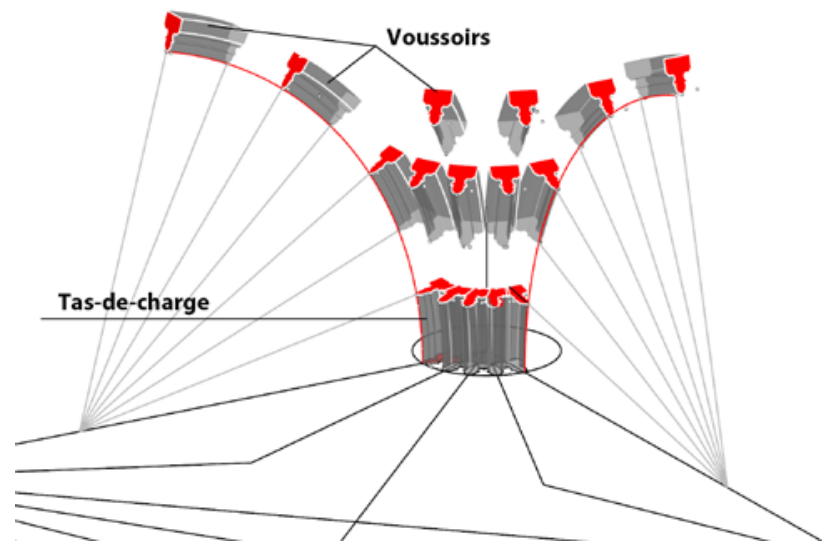

Figure 4. Main components

\section{Quadripartite vault} from 4 parts to 8 parts
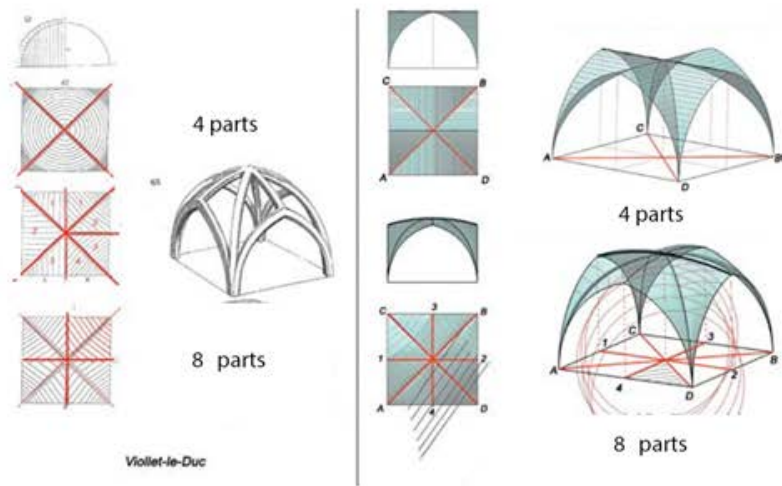

8 parts

Figure 5. ribbed vaults evolution from literature: from quadripartite vault to sexpartite vault, from square to rectangular.

\section{Components - concept definition}

Voussoir: one of the wedge-shaped stones used for rib construction.

Boss or keystone: the voussoir at the top of an arch; in vaulting it occurs at the intersection of the ribs of a rib vault. It is important structurally since it marks the apex of the vault.

Springer: the lowest voussoir on each side of an arch. It is where the vertical support for the arch terminates and the curve of the arch begins.

Tas-de-charge: a French term in architecture, for which there is no equivalent in English, given to the lower courses of a Gothic vault, which are laid in horizontal courses and bonded into the wall, forming a solid mass; they generally rise about one-third of the height of the vault, and as they project forwards they lessen the span to be vaulted over.

We have used these elements and these components to define the algorithmic model, to extract the geometric primitives from point cloud for a realty based 3D model generation, for point cloud labeling, in semantic segmentation process, and for indexing.

\section{GEOMETRIC RULES DEFINITION FOR RIBBED VAULT DESIGN}

In the Middle Ages geometry played an active role in simplifying construction procedures and identifying innovative structural solutions (Capone, 2014). The Livre de Portraiture by Villard de Honnecourt, a key document in studies on Gothic architecture, explains the rationale used to establish the geometric rules applied in ribbed vault erection; these rules are considered the seeds of an evolution which eventually turned primitive Gothic vaults into complex ribbed vaults. A strict system of vaults governs the construction of medieval cathedrals, one in which it is possible to clearly distinguish the small secondary vaults supported by the ribs whose loadbearing function becomes explicit when the groin vault changes and is divided into multiple parts by several secondary elements. The ribbed vaults are based on a structural principle already present in Roman architecture where sometimes the seemingly massive continuous surfaces screen a discontinuous structure, an active masonry frame and an undefined conglomerate filling, two elements, one load-bearing, the other non load-bearing (Capone, 2014).

The simplest rib vault is the quadripartite vault composed by four perimetral arches and two diagonal ribs. The introduction of an intermediate transverse rib transforms the quadripartite vault into sexpartite vault, a ribbed vault whose lateral triangles are bisected by producing six triangles within a bay (Figure 5). Star, stellar or tierceron vaults are generated by introduction of others ribs to divide the web into smaller parts. In each quarter of the vault, two elements, the tiercerons, are placed between diagonal ribs and perimetral arche, staring from the springer (Calvo López, 2020). In in this kind of vault there are four secondary keystones at tiercerons intersection, for this reason this stellar vault is also called: five keystones vault. The five keystones vault transforms into more complex ribbed vaults by introduction of more secondary ribs. These star vaults can be classified in relation to the number of secondary ribs and therefore in relation to the number of divisions of the angle between perimetral arches (Cavallari-Murat, 1958) (Figure 6).

The first ideal model for quadripartite, sexpartite vault and star vault is defined using the Villard rule. The input data for 
algorithm are the plan layout (rectangular, square), the crown line, that can be horizontal straight, inclined or curve, and the ribs cross section, the ribs profile.

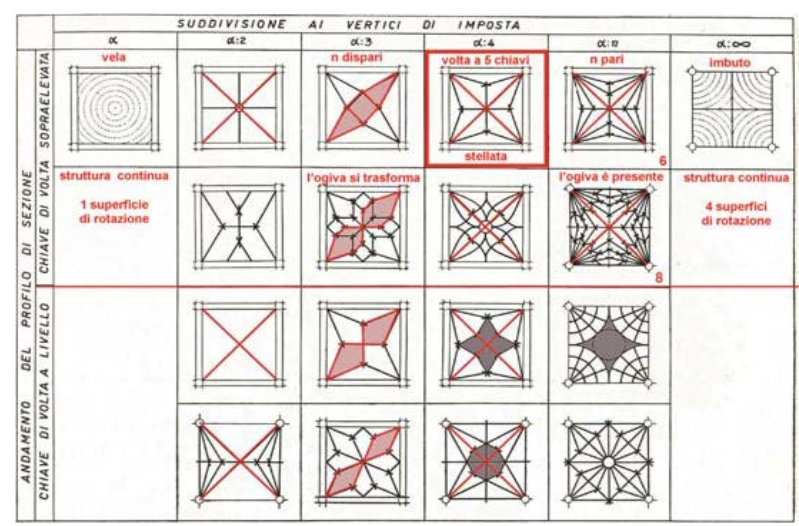

Figure 6. Cavallari-Murat, star vaults classification

\section{PARAMETRIC MODELS FOR RIBBED VAULTS GENERATION}

\subsection{Ribbed vaults generation based on different geometric rules (ideal model)}

In our research we have developed two different parametric models: one is based on geometric rules from Treatises (ideal model) and the other is based on the real ribs geometry (realty based model). The ideal model for quadripartite, sexpartite vault and star vault is defined starting from the Villard rule. In this case, the input data for algorithm are the plan layout (rectangular or square), the ribs shape, that can be horizontal, inclined or curve, and the ribs profiles. Using the Villard rule arches curvature are the same for all. They are composed by arches with the same radius (Figure 7). Starting from diagonal arches we can define the curvature used for the perimetral arches and ribs and we can generate different models in relation to the crown line shape (straight or curve). We have generated the webs using the border profiles extracted from the ribs. We are improving our parametric model using different geometric rules from Spanish, French and English manuals (Figure 8). The input data are the plan size and the output are the different ideal models based on different geometric rule from literature.

Starting from theory we have defined the parameters to use for parametric model and the main steps of the process.

The main differences are about curvature for the arches and ribs that can be the same or not, about ridge ribs that can be horizontal, inclined or curved and diagonal rib geometry that usually is a round arch but it can be also a polycentric arch.

Workflow for parametric model definition:

1.star vault plan definition;

2.extrusion lines definition based on treatises geometric rules;

3.parametric voussoirs parametric model;

4.Tas de charge parametric model;

5.3D model generation using extrusion lines from literature; 6.Web surfaces generation.
Villard de Honnecourt - 3 arches rule
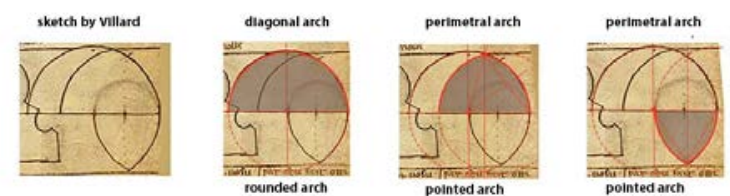

Square plan
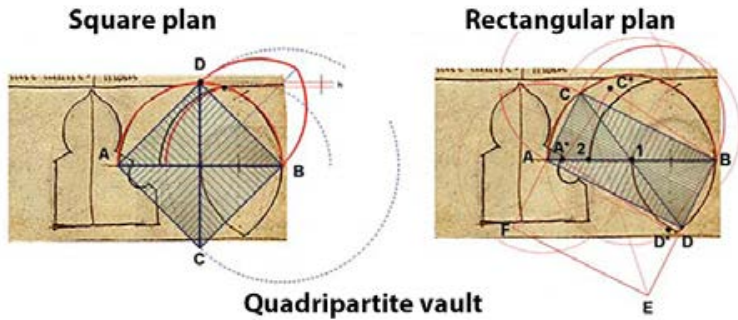

Quadripartite vault
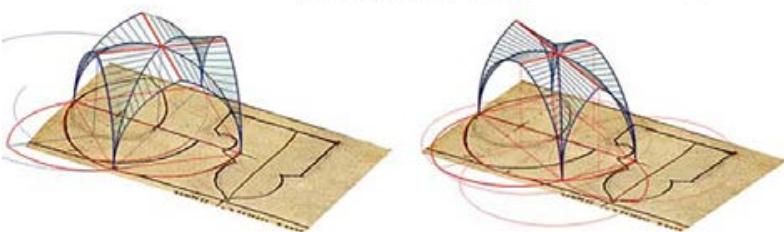

Figure 7. Villard geometric rule for arches generation
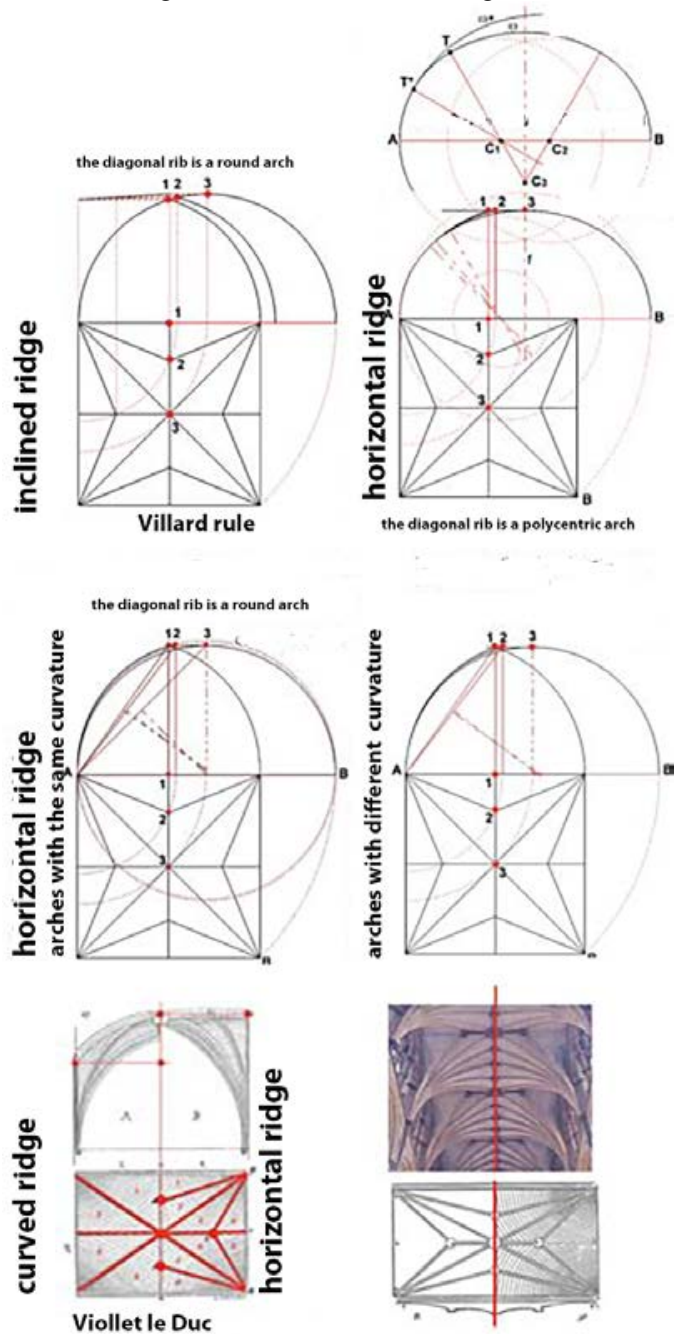

Figure 8. Five keystones vault: different geometric rules from literature. From square to rectangular plan. From horizontal ridge to curved ridge. 
using the same radius

\subsection{STAR VAULTS: an add-on for star vaults generation}

In this paper our aim is to show a part of a research for Star stellar or tierceron vaults. The main goal is to have a set of definitions able to generate different kind of stars vaults using solutions as general as possible. STAR VAULT tool is based on different geometric rules starting from the simplest one: the five keystone vault.

From a methodological point of view, we can group clusters in two groups: clusters to generate MAIN GEOMETRY (plan size, number of ribs, arches shape, extrusion lines...) and clusters to define ELEMENTS (Tas de charge, bosses, voussoir cross section ...).

\section{Main geometry}

Starting from Cavallari Murat star vaults classification we have defined a tool able to generate different kind of star vaults. We have improved Cavallari Murat classification from square plan to rectangular plan.

The parameter is the number of division of angle between diagonal ribs and the plan sides. The angles $\alpha$ and $\beta$ are the same in a square plan vault but they are different if the plan is rectangular.

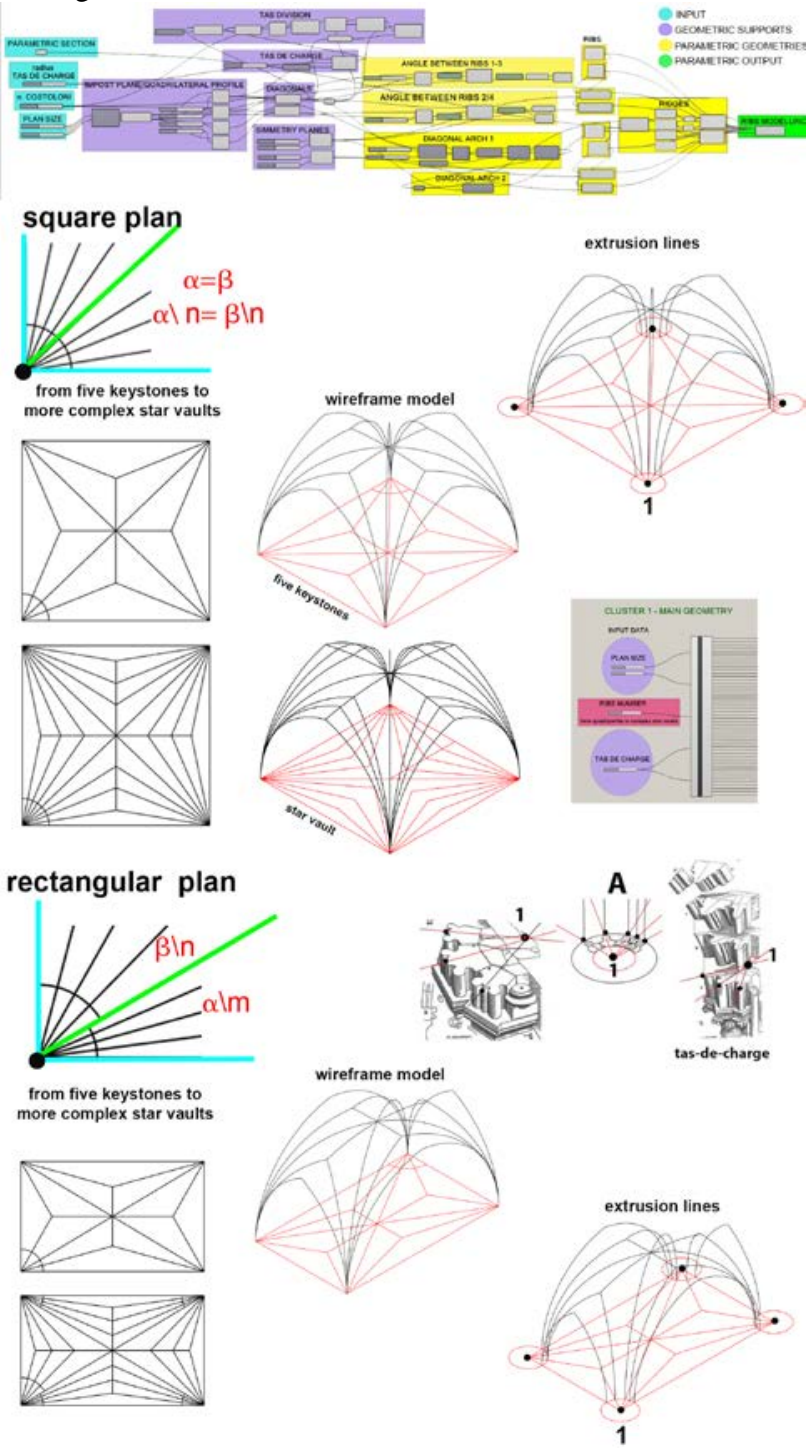

Figure 9. Workflow for parametric model definition. From square to rectangular plan and from five keystones vault to more complex star vaults.

The tool is able to parametrically modify the plan from square to rectangular, allows us to define the tiercerons number and to generate the ribs plan projection (Figure 9).

Using different geometric rules our tool allows us to define the main geometry for each element (diagonal ribs, tiercerons, perimetral arches...) and the extrusion lines in different way. Starting from geometric rules we have generated a simplified model without ribs and arches thickness, without web surfaces between ribs and arches: the wireframe model (Figure 9).

\subsection{Tool for component definition}

Components are the parts which the elements are composed by. The smaller gothic vault component is the main voussoirs and same particular voussoirs such as the keystones or the tas des charges.

Geometry is the base of standardization process of Gothic vaults construction: you can use the same voussoir to build all the arches if the curvature is the same. One of the main goals is to compare 3D model based on geometric rules with case study to verify if a process of standardization had been used or not (Vidal, 2015 ).

Voussoirs can be straight or curved, the ribs can be equal in size and cross-section or not, specific solutions for the tas-decharges, ribs or keystones, different systems can be found to modify or alter what we could consider to be the "geometric integrity" of the design, in order to obtain constructive advantages (Vidal 015).

Starting from this theoretical framework the parameters of our tool are: the voussoir cross section, the profile, the voussoirs shape, straight or curved.

Voussoir parametric model

We have to deal with two questions for voussoir parametric model generation: cross section shape of the ribs and voussoirs longitudinal shape that can be straight or curved. In the ancient rib vaults the voussoirs are small and they are tangent to extrusion line rather than late gothic vaults that have long voussoirs, which therefore have to be curved, cut to follow the same curvature of the corresponding arches.

We have generated a parametric model for ribs and arches cross section based on treatises drawings. This model allows us to generate different ribs section from simplest to more complex samples (Figure 10). If the voussoirs are curved we can generate the model extruding the cross section along the extrusion line, on the contrary, the tool allows to distribute the voussoirs tangent to the extrusion line if they are straight (Figure 11). 


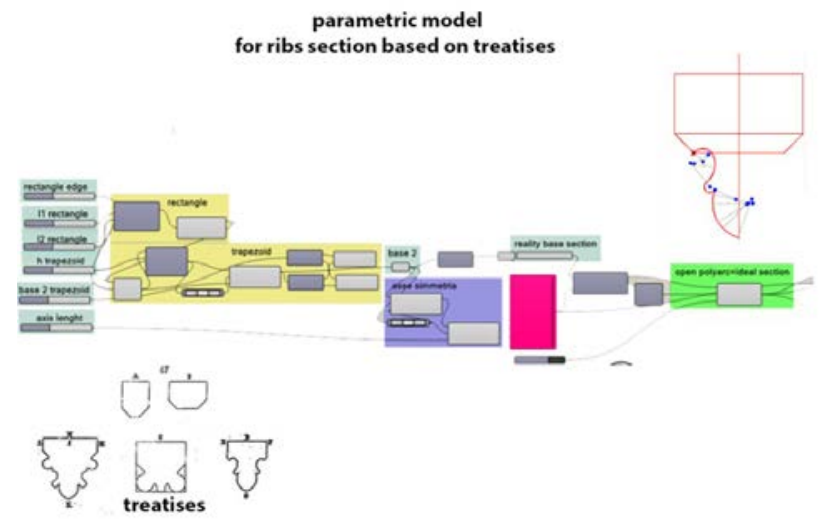

Figure 10. Parametric model for ribs and arches profile based on treatises drawings.

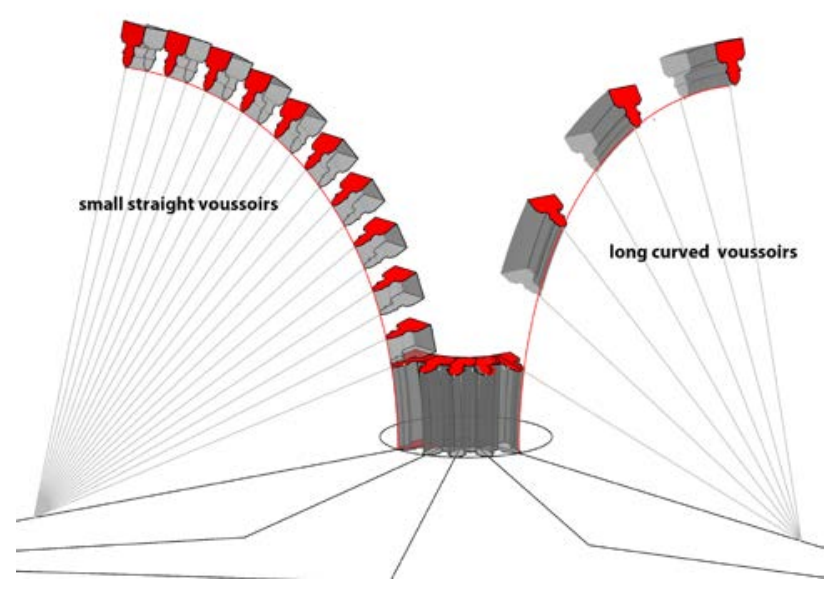

Figure 11. Voussoirs distribution: small straight voussoirs tangent to extrusion line or long curved voussoirs generated moving the cross section along the extrusion line-
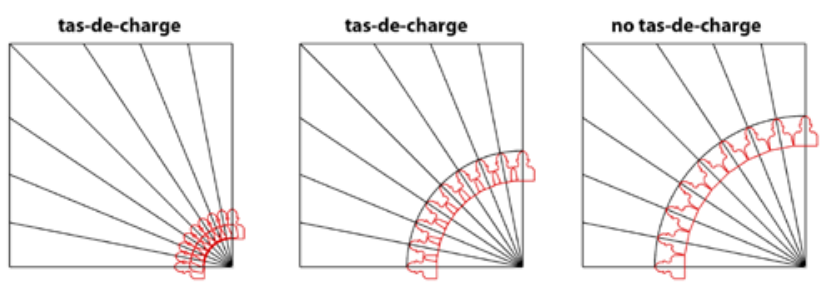

Figure 12. Star vault - Tas de charge parametric model. We can use different cross section profiles and we can parametrically define the extrusion lines geometry and placement in relation to the case study

Tas de charge parametric model

As we know from literature arches and ribs voussoirs can be completely separated on the vault base, spring plane, or they can be superimposed and therefore suitably shaped at the base, in this case there is the so called tas-de-charge (Figure 12). There are no tas-de charges if the arches are separate from each other, they are simply placed one next to the other, and therefore occupy more horizontal space.
It depends on the angle between the selected extrusion lines, on the ribs profiles and on the distance between the plan vertex and the extrusion line location (Figure 12).

In the wireframe model all arches start from the same point, the question to address is the starting point location of the extrusion lines (Angjeliu et al 2019)

Our tool is able to change the extrusion lines location in relation to the case study (Figure 13).

Web, infilling or webbing

The last part of the process is the web generation, the vault surface between the ribs of a rib vault. We have generated webs surfaces using the crown line and border curves from ribs. Each webs is generated using three borders to controls the web curvature.

\section{REALTY BASED MODEL: RIBBED VAULTS GENERATION BASED ON EXTRUSION LINES FROM POINT CLOUD}

We can generate the realty based model using the same parametric model, in this case the input data are the ribs geometry extracted from point cloud.

We use a generative tool to define the curves from point cloud and to draw the extrusion line (in this case they could be arcs of circle) to generate the $3 \mathrm{~d}$ realty based model.

To generate a realty based model from point cloud data, a segmentation that extracts the edges and partitions from point cloud data is necessary and plays an important role in fitting and applying the scan data to the manufacturing process (Woo et al. 2002).

The first step of the process is an algorithm for set points extraction from point cloud and geometry definition of extrusion lines.

To extract planar geometries (perimetral, diagonal, crown and tiercerons arches), we have done the point cloud sections using a series of vertical planes perpendicular to the spring plane (Lanzara et al, 2019). Then, point cloud segments were analyzed according to visual scripting logic. An algorithm allows us to define the curve that best performs fitting on geometry shapes to the given points (Figure 14).

We have tested our tool to study the stellar vault in Castel Nuovo in Naples.

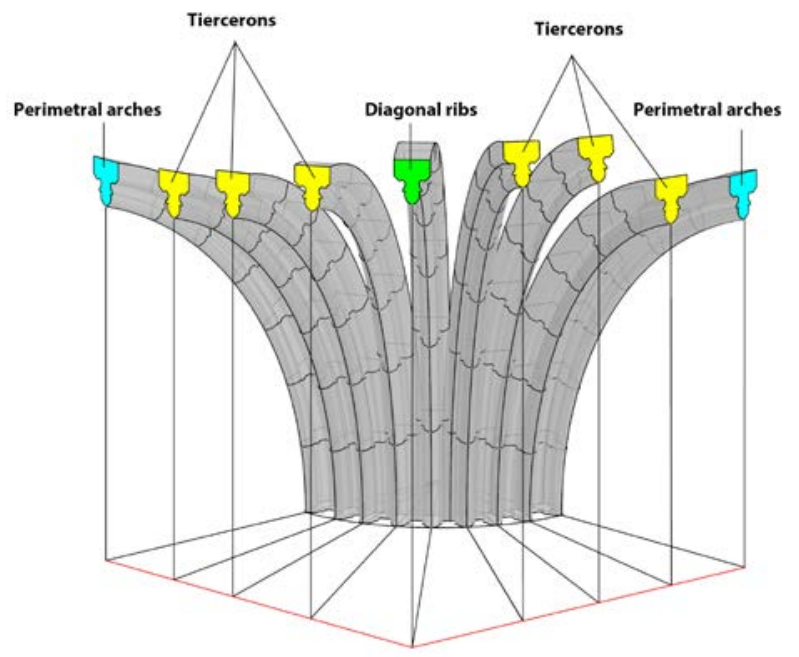




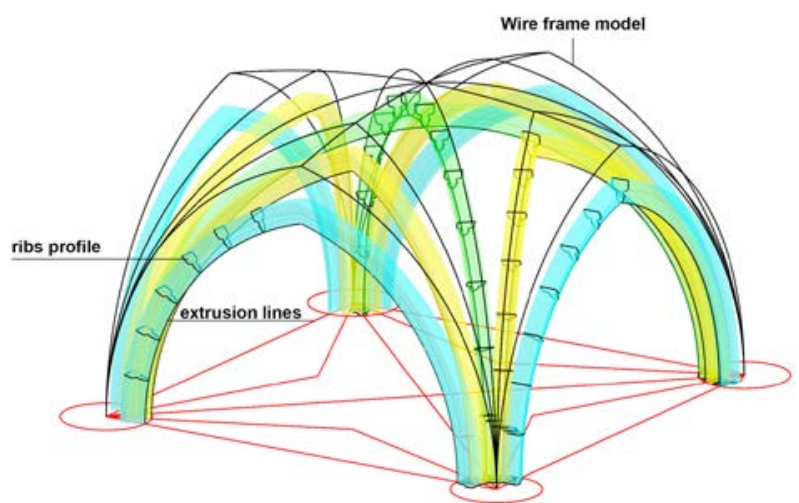

Figure 13. 3D model generated using parametric tool for tas de charges and using ribs and arches profile based on treatises drawings.

The comparison between the 3D ideal models with the model based on point clouds data processing allows us to identify the rule used or to define a new rule and, therefore, to improve the parametric models.

We are testing a workflow for historical architectural elements indexing, for geometries reconstruction in HBIM environment and for point cloud segmentation in DL process.

\section{PARAMETRIC MODEL TESTS FOR POINT CLOUD SEGMENTATION AND 3D RECONSTRUCTIONS}

We can generate the realty based model using the star vault parametric tool, in this case the input data are the ribs geometry extracted from point cloud (Figure 14).

Our tool is able to extract sets of points from point cloud using vertical planes crossing the ribs and to define the curves from these sets of points that, in this case, could be arcs of circle.

\subsection{Case Study: Castel Nuovo five stones vault in Naples}

We have tested our tool to study the five stones vault in the Castel Nuovo in Naples. This is a vault built during the Spanish domination in Naples. After the conquest of the Kingdom of Naples in 1442, Alfonso V of Aragon transformed the Castel Nuovo, an old Angevin fortress in the capital, into a new palace.
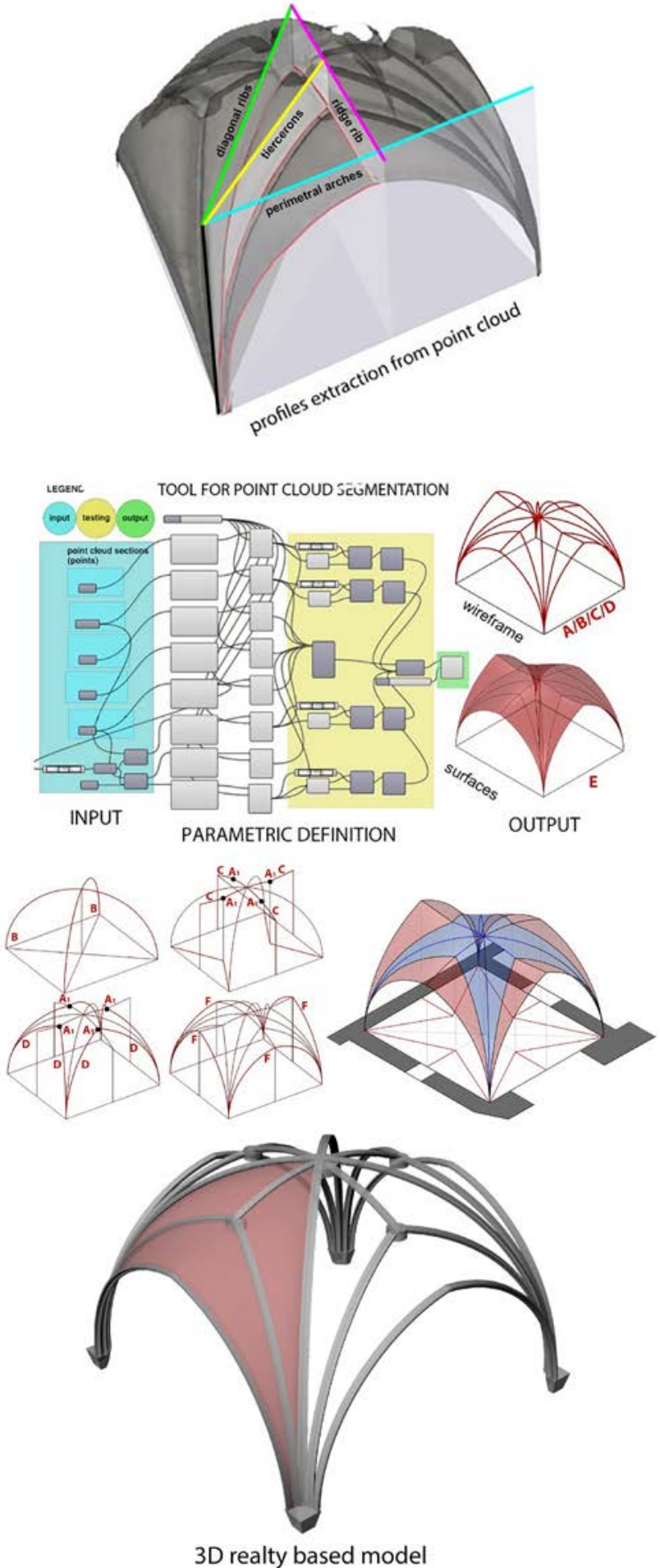

Figure 14. Parametric tool for realty based model generation

In addition to commissioning the well-known triumphal arch ascribed to Francesco Laurana, he ordered the Majorcan architect Guillem Sagrera to construct a number of singular spiral staircases, an octagonal tierceron vault over the castle's main hall, Sala dei Baroni, and a rib vault behind the Laurana arch, that is our case study (Rabasa et. Al., 2012).

We have studied Spanish source for geometric rules to define different kind of "boveda gothica" and to improve our Star Vault Tool able to generate different star vaults. 
We used this rules to improve our parametric model and to define different ideal models based on geometric rules.

We have compared these models with realty based model to verify if one of the rules was used to build the Castel Nuovo vault or to discover a new different rule.

The five stones vault can be generate using different geometric rules that are based on the keystones elevation, the arches curvature and the shape ridge.

We have defined four main kinds of five keystones vault from Spanish literature that can be grouped in relation to arches and ribs curvature: vaults in which the curvature is the same for all arches and ribs or vaults in which the arches and ribs curvature is different.

In the first case the curvature is generally the same as the diagonal arches and the ridge can be horizontal, curved or inclined, therefore, the keystones can be at the same elevation or not. When the keystones are at the same elevation and the curvature is the same, the tiercerons and the perimetral arches are usually raised above vault spring plane.

Knowledge of geometric rules allows us to define the methodological path for the case study. We have done vertical sections in correspondence of the diagonal arches, the perimetral arches, the tiercerons and in correspondence of the ridges (longitudinal and transverse). We have processed these sets of points for each point cloud section using the algorithm and we have defined the circles that best fit these set of points. We have compared the solution for the two diagonal ribs, for the opposite perimetral arches, for the eight tiercerons and for the ridge ribs, to define the best solution for each element to use as input for Star vault tool.

We have compared this realty based model with different ideal models. Overlapping the realty based model to ideal model we are able to understand the vault geometry and the geometric rule used.

\section{CONCLUSIONS}

A tool was developed for procedural modelling and $\backslash$ or point cloud labeling. The algorithms can be implemented and applied to different ribbed vault typologies. Quadripartite vaults, sexpartite vaults and star vaults can be generated from the same algorithm by varying the input data

This demonstrates that an unified 3D modelling procedure has been created, considering different typologies of star vaults rectangular or square in plan (Angjeliu, 2019).

\section{TOOL FOR POINT CLOUD SEMANTIC SEGMENTATION}

\section{diagonal rib- English} nerbio - Spanish. arcs ogives -ffrench

B

\section{Boss, Keystone -English} Clave de boveda - Spanish

A cless de voute

\section{ridge rib-English}

ligadura - Spanish

ligadura- Spanish
Jiemes- French

C linea di cjiave - Italian

tiercerons - English tercelete - Spanish

D Inervatura secondaria - Italia
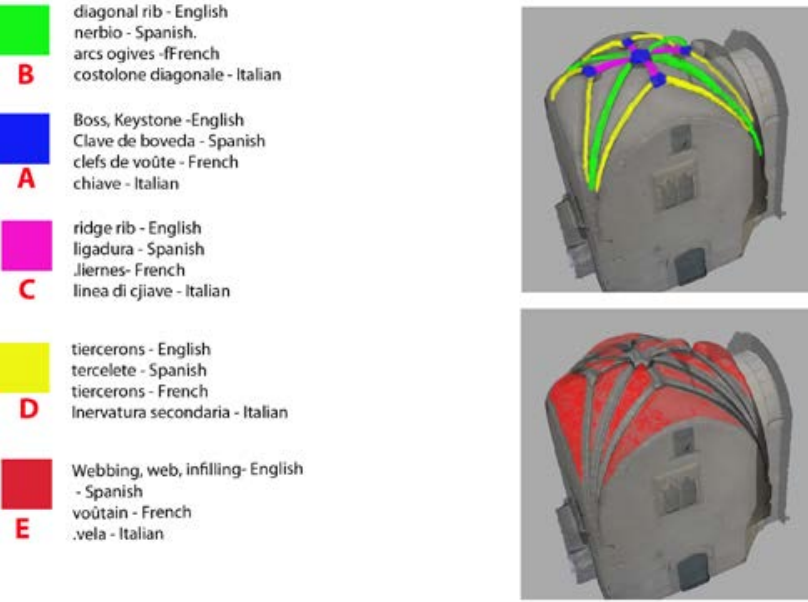

Figure 15. Point cloud sematic segmentation

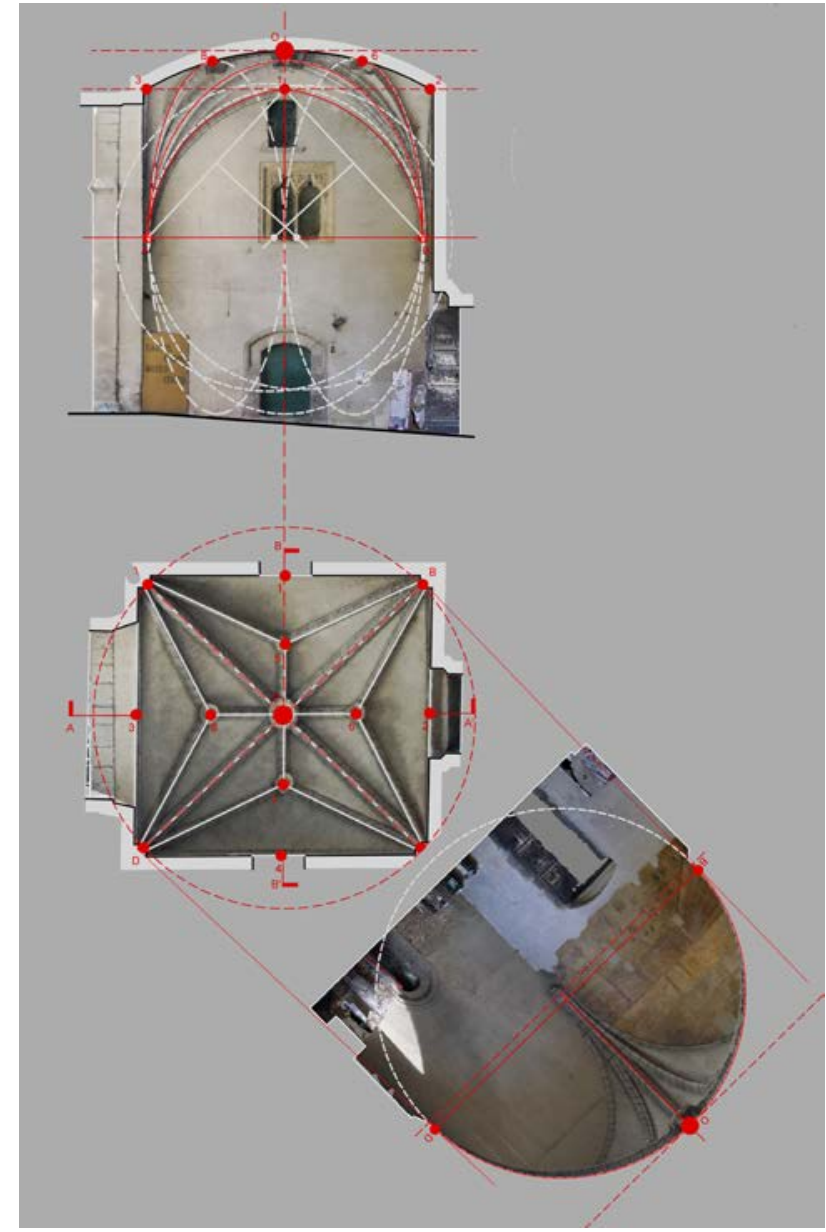

Figure 16. Castel Nuovo five keystones vault in Naples: discover the geometric rules.

We can use the same tool to generate a realty based model using sections from point cloud or ideal model based on geometric rules. Further developments of the model include to implement the model to define more complex star vaults.

We are going to compare our VPL algorithm with commercial HBIM authoring software Edificius (ACCA software), that allows to model different kinds of vaults using new specific parametric objects without any external tools such as Grasshopper or Dynamo. The new toolbar Heritage BIM Edificius provides these parametric objects: Solaio in Legno, Volta, Costola, Area di Degrado, Lesione, Ortofoto e Nicchia.

According to a LOIN (Level Of Information Need) oriented approach, we are going to test its potential to customize the vault elements, such as the parametric object Costola and the possibility to generate 3D models of stars vaults starting from the available types of vaults and testing their possible composition and geometric feautures (e.g. arch types).

\section{REFERENCES}

Angjeliu, G., Cardani, G., Coronelli, D., 2019: A parametric model for ribbed masonry vaults. Elsevier. Automation in Construction. Volume 105, September 2019, 102785

Angjeliu, G, Cardani, G., Coronelli D., 2019. Digital modelling and analysis of masonry vaults. ISPRS - International Archives of the Photogrammetry, Remote Sensing and Spatial Information Sciences. XLII-2/W11, pp 83-89. 
Capone, M. and Lanzara, E., 2019. Scan to BIM vs 3D ideal model. HBIM: parametric tool to study domes geometry, ISPRS, XLII-2/W9, 219-226, https://doi.org/10.5194/isprsarchives-XLII-2-W9-219-2019, 2019.

Capone, M., 2014: La discretizzazione della forma. Genesi e trasformazione: la geometria segreta dei reticoli spaziali delle volte gotiche. The discretisation of form. Genesis and transformation: the secret geometry of spatial tracery in Gothic vaults. Disegnare. Idee immagini. 36-48. Gangemi Editore. n. 49/2014.

Cavallari Murat, A., 1958. Intuizione statica ed immaginazione formale nei reticoli spaziali delle volte gotiche nervate. Rassegna Tecnica. Atti e rassegna tecnica della società degli ingegneri e degli architetti di Torino (n. 7 1958).

Lanzara, E., Samper, A. e Herrera, B., 2019. Point Cloud Segmentation and Filtering to verify the geometric genesis of simple and composed vaults. ISPRS. The International Archives of the Photogrammetry, Remote Sensing and Spatial Information Sciences, Vol. XLII-2/W15, pp. 645-652.

Maira Vidal, R., 2015: The construction of sexpartite vaults in Europe. 5ICCH proceedings, Vol. II : 533-540. ISBN: 978-1329-15031-7.

Martín, R., Maira Vidal, R., 2013: Del trazado a la construcción: Versatilidad de las bóvedas de crucería. Informes de la Construcción Vol. 65, Nº EXTRA-2, 21-34, octubre 2013 doi: 10.3989/ic.13.017

Rabasa, E., López Mozo, A., Gil-Lopez, T., Calvo-López, J., 2012, The 100 Ft Vault: The Construction and Geometry of the Sala dei Baroni of the Castel Nuovo, Naples. Nuts and Bolts of Construction History.

Glossary of Medieval Art and Architecture, http://www.pitt.edu/ medart/menuglossary/INDEX.HTM

Viollet-le-Duc, E. 1854. Dictionnaire raisonné de l'architecture française du Xie au XVIe siècle. Édition Bance-Morel. https://fr.wikisource.org/wiki/Dictionnaire_

Fitchen, J., 1961. The construction of Gothic Cathedrals. A study of Medieval Vault Erection. The University of Chicago Press

Fletcher, F, Banister F., 1905. A History of Architecture on the Comparative Method for the Student, Craftsman, and Amateur. https://victorianweb.org/art/architecture/gothic/12.html

Frézier, A.F., 1739. La théorie et la pratique de la coupe des pierres et des bois ... ou traité de stéréotomie..., 3 vols., Strasbourg-Paris, III, pp. 24-31, plate 71. Digital reproduction available at http://www.e-rara.ch.

Palacios Gonzalo, J. C. 2009. La cantería medieval: la construcion de la bóveda gotica española. Madrid: MunillaLeria, 2009. ISBN: 978-84-8915-084-3.

Calvo-López J., 2020. The geometry of rib vault in early modern Iberian and French literature. Stereotomy: Stone Construction and Geometry in Western Europe 1200-1900 Springer Nature 2020 